\title{
Psychological Well-Being in College Students: Psychometric Properties of the Brief Inventory of Thriving (BIT) and the Comprehensive Inventory of Thriving (CIT)
}

\section{Gökmen Arslan}

\begin{abstract}
The purpose of the present study is to investigate the psychometric properties of two integrative inventories of psychological well-being- the Brief Inventory of Thriving (BIT) and the Comprehensive Inventory of Thriving (CIT) - that could be widely used among Turkish young adults. This study also aimed to examine whether students with severe psychological health symptoms reported higher levels of loneliness, lack of control, and negative feelings, and fewer positive domains of the CIT (e.g., support, belonging, positive feelings, and self-efficacy) than those with mild levels. The participants of this study included 314 Turkish undergraduate students (76\% female with an age range of 18-47 years $[M=22.83, S D=4.09]$ ) from a state university in Turkey. Confirmatory factor analyses showed good psychometric fit statistics of both the CIT and BIT, confirming the latent structure of inventories. Factor loadings of the CIT items were strong, with robust indicator reliabilities. With regard to the concurrent validity of the measures, the study results showed that the domains and the brief version of the measure had significant correlations with psychological health symptoms. Additionally, individuals with severe mental health symptoms reported fewer positive psychological domains of psychological well-being, whereas having higher negative domains of psychological well-being than those with mild symptoms. Specifically, Cohen's d effect sizes were large for some social resources and subjective well-being domains. Overall, these results provide evidence suggesting that both the CIT and BIT could be used to assess psychological well-being among Turkish young adults.
\end{abstract}

Keywords: Thriving, psychological well-being, positive psychology, validity, reliability

Over the past decades, psychological well-being has both theoretically and empirically received increasing attention from researchers and practitioners (Arslan \& Allen, 2021; Renshaw \& Arslan, 2019). It has especially been stated that psychological well-being does not solely consist of the absence of psychological symptoms (e.g., depression, somatization, and anxiety), but also the presence of positive psychological states (e.g., resilience, optimism, happiness, and meaning; Arslan \& Allen, 2020; Furlong et al., 2014; Keyes, 2003; Su et al., 2014; Y1ldırım et al., 2021). Despite this approach focusing on the importance of both negative and positive psychological states in measuring psychological well-being, several scholars have emphasized that research has still predominantly assessed psychological well-being using negative psychological health indicators, such as depression (Bieda et al., 2017; Wiese et al., 2018). A comprehensive picture of the state of psychological well-being, however, could not be provided based on the currently available of psychological health problems. Positive psychological states should also be considered, as they strongly and independently influence the development and course of psychological health disorders (Arslan, 2019; Aziz \& Y1ldırım, 2020; Bieda et al., 2017). The current study aimed to addresses this need by investigating the technical adequacy of both the Comprehensive Inventory of Thriving and Brief Inventory of Thriving ( $\mathrm{Su}$ et al., 2014) with Turkish college students. This study also aimed to examine the association between psychological well-being, namely thriving, constructs and psychological health symptoms among college students.

Department of Psychological Counseling and Guidance, Mehmet Akif Ersoy University, Burdur, Turkey

Corresponding Author: Gökmen Arslan, Department of Psychological Counseling and Guidance, Faculty of Education, Mehmet Akif Ersoy University, Burdur, Turkey.

Email: garslan@mehmetakif.edu.tr 


\section{Comprehensive Inventory of Thriving (CIT)}

According to Su et al. (2014), the term thriving refers to "the state of positive functioning at its fullest rangementally, physically, and socially" (p. 256). Theoretically, the term corresponds to psychological well-being, and the measure is thus developed to assess a broad range of well-being constructs (Sorgente et al., 2021; Su et al., 2014). Psychological well-being is a multifaceted construct encompassing various domains of human positive psychological functioning and wellbeing (Arslan \& Renshaw, 2018; Ryff \& Keyes, 1995). Su et al. (2014) have recently attempted to synthesize the literature on psychological well-being and stated seven core dimensions of this construct: subjective well-being (life satisfaction, positive feelings, and negative feelings), engagement in daily activities, purpose and meaning in life, supportive positive relationships (social support, respect, community, loneliness, trust, and belongingness), autonomy, sense of mastery and accomplishment (skill, accomplishment, learning, self-efficacy, and self-worth), and optimism. These latent constructs are identified in 18 sub-scales of thriving, each comprising of three items. Specifically, the measure has integrated key hedonic and eudaimonic approaches by providing a comprehensive framework in understanding one's positive psychological functioning and wellbeing (Sorgente et al., 2021). Therefore, research is warranted to validate such inventories of psychological well-being in order to provide an understanding of how to foster well-being and mental health at the international level.

Subjective well-being, the first domain of psychological well-being, refers to subjectively experienced a feeling of satisfaction, a prevalence of positive feelings, and an infrequency of negative feelings (Diener, 1984; Diener et al., 1999). The second domain, engagement, refers to flow, which takes place when people are fully absorbed in their daily activities, experiencing a feeling of energized excitement (Wiese et al., 2018). Third, purpose and meaning in life is an essential aspect of psychological well-being referring to the degree to which people feel their life is meaningful and purposeful (Arslan, 2020; Arslan, \& Yıldırım, 2021; Wiese et al., 2018; Y1ldırım, \& Arslan, 2021). Supportive and enriching positive relationships, the fourth dimension of psychological well-being, emphasizes the importance of social relations in psychological health and the protective effect of social connections on psychological well-being in times of stress (Arslan, 2018; Wiese et al., 2018; Yıldırım \& Arslan, 2020; Y1ldırım et al., 2020).). Another important aspect of psychological well-being is autonomy, which is a belief that an individual has control over her or his life (Ryan \& Deci, 2000; Ryff \& Keyes, 1995). The sixth domain of psychological wellbeing is feelings of mastery and accomplishment that can be identified as holding the appropriate skills to do things, the belief and confidence in applying those skills, and the feelings of achievement after using those skills. Lastly, optimism is another important domain of psychological well-being, which is a mindset that is a tendency to expect positive outcomes in life (Carver, 2014; Scheier \& Carver, 1985).

Although there is evidence indicating that each of these domains is an important indicator of psychological well-being, a few of these constructs have been assessed by existing measures. For example, Butler and Kern (2016) developed a measure to assess flourishing based on Seligman's PERMA model, which measures five dimensions of flourishing including positive emotions, engagement, social relationships, meaning, and accomplishment. The Satisfaction with Life Scale is another example widely used measure of psychological well-being (Diener et al., 1985), and the scale assesses one facet of wellbeing. However, these measures do not provide a comprehensive framework of all core dimensions of psychological wellbeing. Developing a comprehensive inventory to assess a broad range of psychological well-being can thus be useful to develop prevention and intervention strategies to foster mental health and wellbeing. Su et al. (2014) have emphasized that the CIT can serve as a screening tool for psychological well-being to distinguish people in the strength or weakness. Although the measure has provided a comprehensive framework on psychological well-being, the original 18-factor structure has been rarely replicated. Several validation studies run the 18 -factor measurement model, but the model was slightly modified, resulting in a higher or lower number of degrees of freedom than in the original model (see, Sorgente et al., 2021). For example, Wiese et al. (2018) tested the original 18-factor model across 10 countries, including a Turkish community sample, indicating that the original measurement model did not provide well data-model fit statistics for all the data. Therefore, the present study aims to psychometrically evaluate the CIT and BIT with the replicating the validity done in previous studies and to explore the association between psychological well-being constructs and psychological health symptoms among the Turkish young adult sample. In this regard, we expected that the scale would yield a multidimensional scale as produced in the original form. 


\section{Participants}

\section{Method}

The participants of this study included 314 undergraduate students (76\% female with an age range of 18-47 years $[M=22.83, S D=4.09])$ from a state university in an urban city, Turkey. An online web-based survey was created using the study questionnaires and demographic items. Then, the survey was applied to students who volunteered to participate in the study during distance education. All participants in the present study have reviewed and signed the informed consent form before starting the data collection. The study also was approved by the institutional review board.

\section{Measures}

Comprehensive Inventory of Thriving (CIT) and Brief Inventory of Thriving (BIT). The CIT is a 54item self-report measure developed to assess psychological wellbeing domains (Su et al., 2014). It has 18 subscales, each of which is assessed by three items that map on to seven psychology constructs, representing a higher-order latent construct, called thriving as described in the introduction section. All items are responded using a 5-point response rating scale, ranging from strongly disagree (1) to strongly agree (5) with higher scores reflecting psychological well-being. The brief version of the measure is comprised of 10 items reflecting those psychological wellbeing domains. Previous research showed that both inventories had acceptable data-model fit statistics, with adequate-to-strong internal reliability estimates. Further evidence supported concurrent and predictive validity of the inventories with some well-being and psychological health indicators (see Sorgente et al., 2021 for more information).

Although the inventories were translated into the Turkish language (Diener, 2021), to the best of our knowledge, there is no evidence indicating the psychometric properties of the measures with Turkish young adults. For the current study, the Turkish version of the CIT created by Diener, and colleagues was used (Wiese et al., 2018); however, before administrating the process, two independent experts working in counseling psychology reviewed this translation, who checked the wording of the scale to account for cultural and readability considerations. Based on their recommendations, many items of the measure were revised and updated the translation form (e.g., "I feel a sense of belonging in my community", "In most ways, my life is close to my ideal," "What I do in life is valuable, and worthwhile"). Like the original version, the final Turkish version of the CIT included 54 items responded using the same 5-point Likert type scale.

The Brief Symptom Inventory (BSI- I8). The BSI-18 was used to measure the mental health symptoms of college students (Derogatis \& Fitzpatrick, 2004). The BSI-18 is an 18-item self-report rating scale, consisting of six-item subscales: anxiety, depression, and somatization (e.g., "Feeling no interest in things", "Pains in heart or chest"). All items of the scale are scored based on a 5-point Likert type scale, ranging from not at all (0) to very much (4). Previous research reported that the scale had a strong internal reliability estimate for Turkish young adults (Arslan, Yıldırım, et al., 2020). For this study, the internal reliability estimates of the measures ranged from .88 to .95 .

\section{Data Analyses}

Confirmatory factor analysis was first performed to affirm the factor structure of both the CIT and BIT, which was described in the development study of the inventories (Su et al., 2014). Several data-model fit statistics were utilized to assess the goodness of fit of the measurement model: standardized root mean squared residual (SRMR) and root mean square error of approximation (RMSEA) $\leq .08$ and Tucker-Lewis index (TLI) and comparative fit index (CFI) $\geq .90$ = adequate data-model fit (Hooper et al., 2008; Kline, 2015). After evaluating the factor structure of the measure, descriptive statistics, and the associations of thriving constructs with psychological health indicators. Normality assumption for the measures of the study was examined using skewness and kurtosis scores and their cutoff values (Curran et al., 1996). Finally, participants were categorized into two groups to compare the effects of groups. The cutoff scores of the BSI-18 were used to divide the participants into two groups: severe psychological symptom level > 2.14 and mild psychological symptom level $\leq 2.14$ (Dağ, 1991). A series of univariate analyses of variance (ANOVAs) were carried out to compare those groups based on psychological well-being constructs. Findings from these analyses were evaluated using the Cohen's $d$ effect sizes with decisions points: small $d=.2$, medium $d=.5$, and large $d=.8$ (Cohen, 1988). All statistical analyses of the study were performed with jamovi version 2.0 (The jamovi project, 2021) and IBM SPSS Statistics 25. 
Table I. Confirmatory factor analysis results

\begin{tabular}{|c|c|c|}
\hline Factor & Indicator & Stand. Estimate \\
\hline \multirow{3}{*}{ Support } & There are people I can depend on to help me & .90 \\
\hline & There are people who give me support and encouragement & .95 \\
\hline & There are people who appreciate me as a person & .85 \\
\hline \multirow[t]{3}{*}{ Community } & I pitch in to help when my local community needs something done & .85 \\
\hline & I invite my neighbors to my home & .73 \\
\hline & I look for ways to help my neighbors when they are in need & .84 \\
\hline \multirow[t]{3}{*}{ Trust } & I can trust people in my society & .89 \\
\hline & People in my neighborhood can be trusted & .89 \\
\hline & Most people I meet are honest & .77 \\
\hline \multirow[t]{3}{*}{ Respect } & People respect me & .92 \\
\hline & People are polite to me & .89 \\
\hline & I am treated with the same amount of respect as others & .80 \\
\hline \multirow[t]{3}{*}{ Loneliness } & I feel lonely & .76 \\
\hline & I often feel left out & .90 \\
\hline & There is no one I feel close to & .78 \\
\hline \multirow[t]{3}{*}{ Belonging } & I feel a sense of belonging in my community & .83 \\
\hline & I feel a sense of belonging in my state or province & .88 \\
\hline & I feel a sense of belonging in my country & .67 \\
\hline \multirow[t]{3}{*}{ Engagement } & I get fully absorbed in activities I do & .74 \\
\hline & In most activities I do, I feel energized & .89 \\
\hline & I get excited when I work on something & .89 \\
\hline \multirow[t]{3}{*}{ Skills } & I use my skills a lot in my everyday life & .92 \\
\hline & I frequently use my talents & .90 \\
\hline & I get to do what I am good at everyday & .74 \\
\hline \multirow[t]{3}{*}{ Learning } & I learned something new yesterday & .75 \\
\hline & Learning new things is important to me & .83 \\
\hline & I always learn something everyday & .83 \\
\hline \multirow[t]{3}{*}{ Lack of control } & Other people decide most of my life decisions (R) & .82 \\
\hline & The life choices I make are not really mine $(\mathrm{R})$ & .90 \\
\hline & Other people decide what I can and cannot do (R) & .89 \\
\hline \multirow[t]{3}{*}{ Accomplishment } & I am achieving most of my goals & .87 \\
\hline & I am fulfilling my ambitions & .92 \\
\hline & I am on track to reach my dreams & .86 \\
\hline \multirow[t]{3}{*}{ Self-Efficacy } & I can succeed if I put my mind to it & .82 \\
\hline & I am confident that I can deal with unexpected events & .88 \\
\hline & I believe that I am capable in most things & .86 \\
\hline \multirow[t]{3}{*}{ Self-Worth } & What I do in life is valuable and worthwhile & .88 \\
\hline & The things I do contribute to society & .87 \\
\hline & The work I do is important for other people & .79 \\
\hline \multirow[t]{3}{*}{ Meaning } & My life has a clear sense of purpose & .84 \\
\hline & I have found a satisfactory meaning in life & .91 \\
\hline & I know what gives meaning to my life & .92 \\
\hline \multirow[t]{3}{*}{ Optimism } & I am optimistic about my future & .86 \\
\hline & I have a positive outlook on life & .93 \\
\hline & I expect more good things in my life than bad & .73 \\
\hline \multirow[t]{3}{*}{ Life satisfaction } & In most ways my life is close to my ideal & .80 \\
\hline & I am satisfied with my life & .92 \\
\hline & My life is going well & .93 \\
\hline \multirow[t]{3}{*}{ Positive feelings } & I feel positive most of the time & .94 \\
\hline & I feel happy most of the time & .96 \\
\hline & I feel good most of the time & .92 \\
\hline \multirow[t]{3}{*}{ Negative feelings } & I feel negative most of the time $(\mathrm{R})$ & .90 \\
\hline & I experience unhappy feelings most of the time (R) & .95 \\
\hline & I feel bad most of the time $(\mathrm{R})$ & .90 \\
\hline
\end{tabular}


Table 2. Descriptive statistics of the measures

\begin{tabular}{lcccccc}
\hline & Mean & SD & Skewness & Kurtosis & $\alpha$ & $\omega$ \\
\hline CIT & - & - & - & - & .96 & .97 \\
$\quad$ Support & 12.19 & 3.34 & -1.28 & .86 & .92 & .93 \\
Community & 11.35 & 3.14 & -.83 & .12 & .84 & .85 \\
Trust & 9.40 & 3.28 & -.15 & -.65 & .88 & .88 \\
Respect & 10.94 & 2.97 & -.81 & .47 & .90 & .91 \\
Loneliness & 6.59 & 3.34 & .82 & -.24 & .85 & .85 \\
Belonging & 9.56 & 3.50 & -.29 & -.87 & .83 & .84 \\
Engagement & 10.78 & 2.89 & -.46 & -.12 & .88 & .88 \\
Skills & 10.30 & 3.08 & -.40 & -.23 & .89 & .89 \\
Learning & 10.88 & 2.90 & -.49 & -.21 & .84 & .85 \\
Lack of control & 6.33 & 3.28 & .82 & -.06 & .90 & .90 \\
Accomplishment & 10.46 & 2.92 & -.46 & -.11 & .91 & .91 \\
Self-efficacy & 11.46 & 2.89 & -.76 & .23 & .89 & .89 \\
Self-worth & 10.97 & 3.00 & -.66 & .07 & .89 & .89 \\
Meaning & 10.32 & 3.30 & -.39 & -.62 & .91 & .92 \\
Optimism & 9.93 & 3.47 & -.42 & -.69 & .87 & .88 \\
Life satisfaction & 9.73 & 3.24 & -.42 & -.46 & .91 & .91 \\
Positive feelings & 9.79 & 3.46 & -.38 & -.71 & .96 & .96 \\
Negative feelings & 7.74 & 3.32 & .40 & -.55 & .94 & .94 \\
BIT & 34.99 & 8.62 & -.63 & -.02 & .91 & .91 \\
\hline
\end{tabular}

\section{Results}

Confirmatory factor analyses were performed to test the factor structure of the previously known CIT and BIT. Findings from factor analysis for the CIT measurement model, which structured each of the 54 items as indicators of the 18 thriving constructs (e.g., support, learning, life satisfaction, etc.), indicated adequate-data model fit statistics- $\chi^{2}=2485, d f=1224, p<.001, \mathrm{CFI}=.92, \mathrm{TLI}=.91$, RMSEA [95\% CI] $=.057[.054, .060], \mathrm{SRMR}=$ .043. Factor loadings of the CIT items were strong and ranged between .67 and .96 as seen in Table 1. Further confirmatory factor analysis was conducted to test the BIT measurement model that structured each of the 10 items loading to the BIT construct, indicating good data-model fit statistics $-\chi^{2}=106, d f=32, p<.001, \mathrm{CFI}=.96$, TLI $=$ .95 , RMSEA $[95 \% \mathrm{CI}]=.056[.068, .10], \mathrm{SRMR}=.042$.

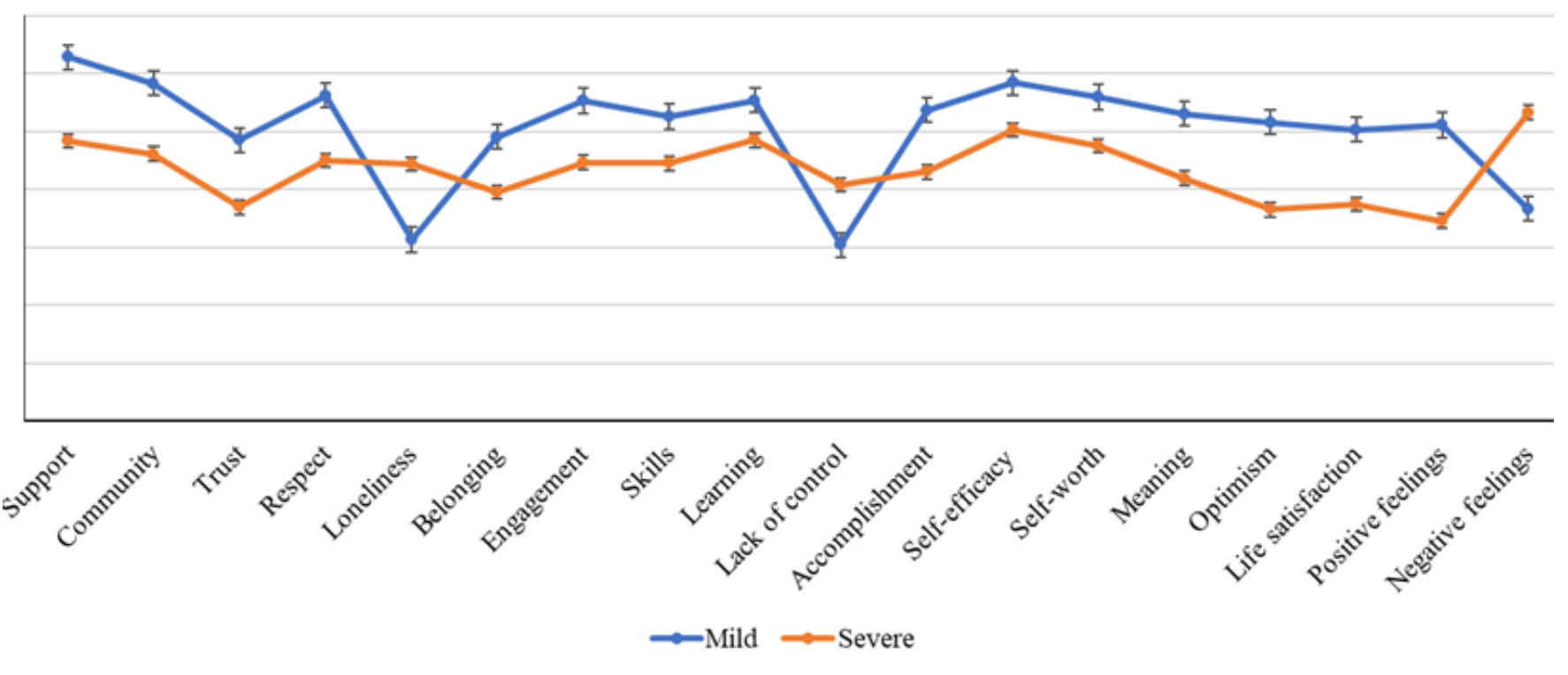

Figure I. A compression between people with mild and severe psychological health symptoms on the psychological well-being domains 
Factor loadings of the BIT items were adequate-to-strong and ranged between .32 (I feel a sense of belonging in my community) and .87 (What I do in life is valuable and worthwhile). These results provide evidence suggesting that both the CIT and BIT could be used to assess student psychological well-being in higher education.

After confirming the factor structure of the inventories, descriptive statistics, the assumption of normality, and internal reliability estimates of the inventories were examined. Skewness and kurtosis values ranged between -1.28 and .86, suggesting that all variables had a relatively normal distribution. Descriptive statistics also demonstrated that the internal reliability estimates of the measures were strong and ranging between .84 and .97 , as shown in Table 2. Pearson correlation analysis was then conducted to investigate the association between thriving constructs and criterion variables including psychological health symptoms (i.e., depression, somatization, and anxiety). Findings from this analysis showed that all thriving subscales and the BIT had significant and small-to-large associations with psychological health symptoms, as seen in Table 3. Most subscales of the CIT and the BIT had negative correlations with the three measures of psychological health symptoms (positive associations for the three negatively worded scales of the CIT; see Table 3), suggesting further evidence for their validity.

Lastly, a series of univariate ANOVAs were utilized to compare the effect of psychological symptom groups on young adults' thriving constructs, as shown in Table 4. Findings from these analyses yielded a significant main effect of psychological symptom levels on all constructs. Cohen's $d$ effect sizes were moderate to large, ranging from .47 for learning to 1.06 for negative feelings. Additionally, the findings indicated a significant main effect of psychological health symptom levels on the BIT. The Cohen's $d$ effect size was .98 for BIT scores. These results indicate that participants with severe psychological health symptoms report lower levels of positive psychological domains of psychological well-being, whereas having greater negative domains of psychological well-being than those with mild symptom levels, as seen in Figure 1.

\section{Discussion}

The present study aimed to examine the psychometric properties of two integrative measures of psychological wellbeing- the Comprehensive Inventory of Thriving (CIT) and Brief Inventory of Thriving (BIT)- that could be widely used among Turkish young adults. This study also aimed to examine the association between psychological wellbeing constructs and psychological health symptoms and to explore whether students with severe psychological health symptoms reported higher levels of loneliness, lack of control, and negative feelings, and fewer positive domains of the CIT (e.g., support, belonging, positive feelings, and self-efficacy) than those with mild symptoms.

Confirmatory factor analyses showed good psychometric fit statistics of both the CIT and BIT, confirming the latent structure of inventories. Factor loadings of the CIT items were strong, with robust indicator reliabilities. Additionally, the factor loadings of the BIT ranged adequate to large. Consistent with the results, previous studies have found that both inventories provided adequate psychometric fits in a few different cultural groups, such as Chinese (Duan et al., 2016), Brazilian (Martins \& Ferreira, 2018), and Italian (Andolfi et al., 2017) samples. These results were also consistent with the original study report (Su et al., 2014). While the original study (Su et al., 2014) reported the 18-factor structure of the CIT, some validation research indicted alternative factorial structures of the CIT (Sorgente et al., 2021; Wiese et al., 2018). A study by Wiese et al. (2018) examined the measurement invariance of these two measures across 10 countries, including a Turkish community sample (196 participants), without examining other aspects of validity evidence (e.g., convergent, and criterion validity), indicating that the inventories provided poor-to-acceptable data-model fit statistics. Furthermore, internal consistency reliability estimates of the thriving measure and its subscales were strong, which has also been supported by past studies (Martins \& Ferreira, 2018; Sorgente et al., 2021; Su et al., 2014; Wiese et al., 2018). Taken together, the findings of this study provide strong evidence in support of both the CIT and BIT and suggests that these inventories are efficacious and robust tools for measuring psychological well-being among Turkish young adults. The present study, therefore, contributes to the body of literature on the assessments of psychological wellbeing among diverse populations.

With regard to the concurrent validity of the thriving constructs, the study results showed that the domains and the brief version of the measure had significant correlations with psychological health indicators, including depression, anxiety, and somatization. These findings were consistent with previous research indicating that thriving domains were significantly associated with various psychological and physical health and well-being indicators (Sorgente et al., 2021; Su et al., 2014). 


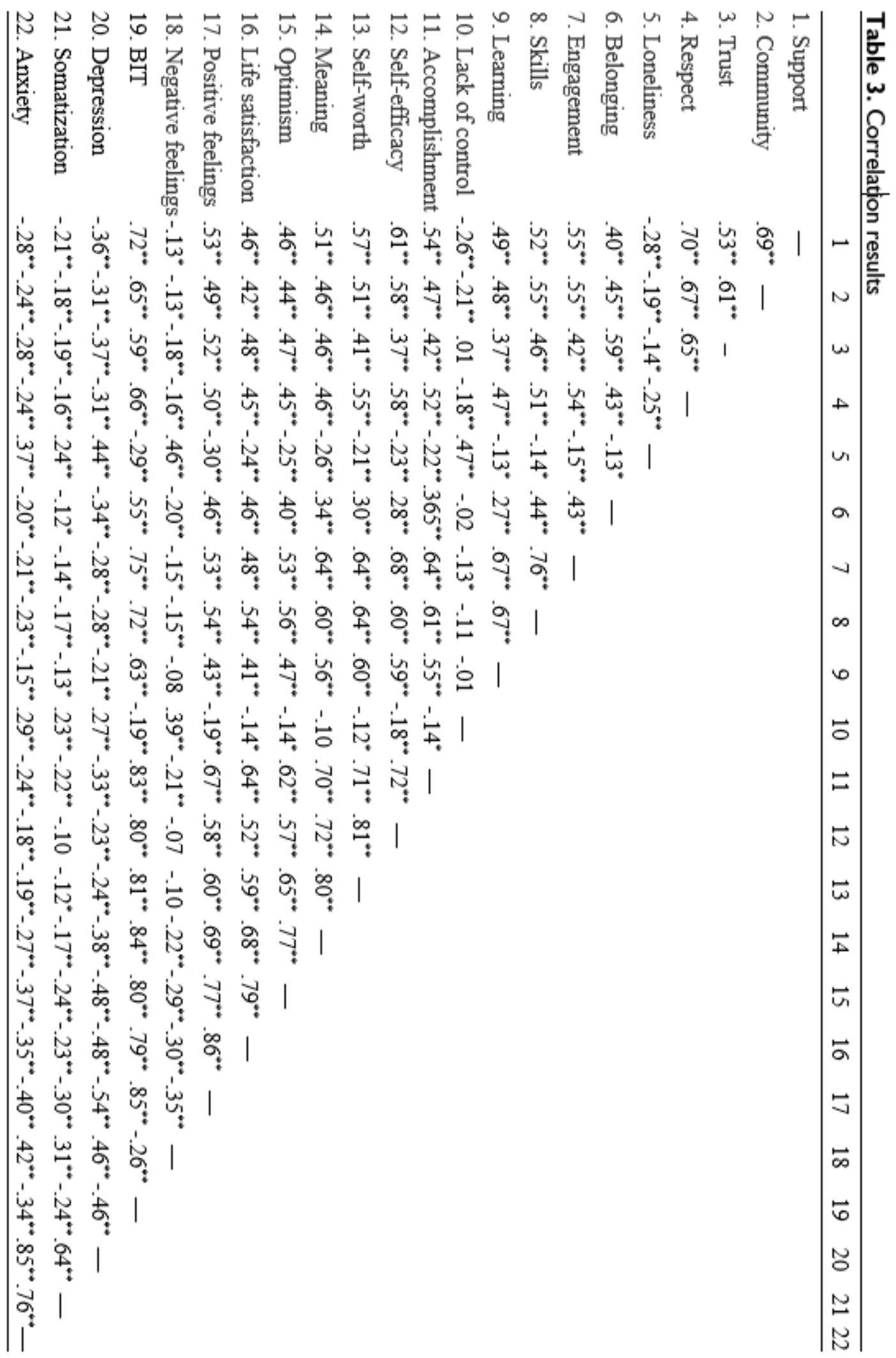


Table 4. Univariate analysis of variance results

\begin{tabular}{|c|c|c|c|c|c|c|c|c|}
\hline \multirow{2}{*}{ Variable } & & \multirow[b]{2}{*}{$M$} & \multirow[b]{2}{*}{$S D$} & \multirow[b]{2}{*}{$F$} & \multirow[b]{2}{*}{$p$} & \multirow[b]{2}{*}{ Cohen's $d$} & \multicolumn{2}{|c|}{$95 \%$ CI } \\
\hline & & & & & & & Lower & Upper \\
\hline \multirow[t]{2}{*}{ Support } & Mild level & 12.55 & 2.99 & 28.20 & $<.001$ & .90 & .56 & 1.24 \\
\hline & Severe level & 9.67 & 4.41 & & & & & \\
\hline \multirow{2}{*}{ Community } & Mild level & 11.66 & 2.93 & 22.38 & $<.001$ & .80 & .46 & 1.14 \\
\hline & Severe level & 9.22 & 3.71 & & & & & \\
\hline \multirow[t]{2}{*}{ Trust } & Mild level & 9.70 & 3.15 & 18.43 & $<.001$ & .73 & .39 & 1.06 \\
\hline & Severe level & 7.37 & 3.53 & & & & & \\
\hline \multirow[t]{2}{*}{ Respect } & Mild level & 11.23 & 2.77 & 20.90 & $<.001$ & .77 & .43 & 1.11 \\
\hline & Severe level & 9.00 & 3.56 & & & & & \\
\hline \multirow[t]{2}{*}{ Loneliness } & Mild level & 6.25 & 3.13 & 22.84 & $<.001$ & .81 & -1.15 & -.47 \\
\hline & Severe level & 8.87 & 3.84 & & & & & \\
\hline \multirow[t]{2}{*}{ Belonging } & Mild level & 9.80 & 3.34 & 10.68 & $<.001$ & .55 & .22 & .89 \\
\hline & Severe level & 7.90 & 4.08 & & & & & \\
\hline \multirow[t]{2}{*}{ Engagement } & Mild level & 11.05 & 2.61 & 20.07 & $<.001$ & .76 & .42 & 1.10 \\
\hline & Severe level & 8.92 & 3.92 & & & & & \\
\hline \multirow[t]{2}{*}{ Skills } & Mild level & 10.50 & 2.92 & 9.75 & .002 & .53 & .19 & .86 \\
\hline & Severe level & 8.90 & 3.77 & & & & & \\
\hline \multirow[t]{2}{*}{ Learning } & Mild level & 11.06 & 2.74 & 7.83 & .005 & .47 & .13 & .81 \\
\hline & Severe level & 9.70 & 3.63 & & & & & \\
\hline \multirow[t]{2}{*}{ Lack of control } & Mild level & 6.07 & 3.13 & 14.53 & $<.001$ & .65 & -.98 & -.31 \\
\hline & Severe level & 8.15 & 3.76 & & & & & \\
\hline \multirow[t]{2}{*}{ Accomplishment } & Mild level & 10.73 & 2.67 & 19.77 & $<.001$ & .75 & .41 & 1.09 \\
\hline & Severe level & 8.60 & 3.78 & & & & & \\
\hline \multirow[t]{2}{*}{ Self-efficacy } & Mild level & 11.67 & 2.68 & 11.33 & $<.001$ & .57 & .23 & .91 \\
\hline & Severe level & 10.05 & 3.82 & & & & & \\
\hline \multirow[t]{2}{*}{ Self-worth } & Mild level & 11.18 & 2.76 & 11.32 & $<.001$ & .57 & .23 & .90 \\
\hline & Severe level & 9.50 & 4.08 & & & & & \\
\hline \multirow[t]{2}{*}{ Meaning } & Mild level & 10.60 & 3.08 & 16.71 & $<.001$ & .69 & .35 & 1.03 \\
\hline & Severe level & 8.37 & 4.06 & & & & & \\
\hline \multirow[t]{2}{*}{ Optimism } & Mild level & 10.31 & 3.20 & 28.59 & $<.001$ & .91 & .56 & 1.25 \\
\hline & Severe level & 7.30 & 4.12 & & & & & \\
\hline \multirow[t]{2}{*}{ Life satisfaction } & Mild level & 10.06 & 2.98 & 2385 & $<.001$ & .83 & .49 & 1.17 \\
\hline & Severe level & 7.47 & 3.99 & & & & & \\
\hline \multirow[t]{2}{*}{ Positive feelings } & Mild level & 10.21 & 3.16 & 35.39 & $<.001$ & 1.01 & .66 & 1.35 \\
\hline & Severe level & 6.90 & 4.09 & & & & & \\
\hline \multirow[t]{2}{*}{ Negative feelings } & Mild level & 7.32 & 2.94 & 39.14 & $<.001$ & 1.06 & -1.40 & -.72 \\
\hline & Severe level & 10.65 & 4.27 & & & & & \\
\hline BIT & Mild level & 36.01 & 7.71 & 33.49 & $<.001$ & .98 & .64 & 1.32 \\
\hline & Severe level & 27.97 & 11.05 & & & & & \\
\hline
\end{tabular}

For example, Duan et al. (2016) reported the significant associations between the BIT and some well-being (e.g., flourishing, meaning in life) and psychological symptoms, including depression, anxiety, and stress. Consistent with the literature, findings from this study also revealed that individuals with severe psychological health symptoms reported fewer positive psychological domains of psychological well-being, whereas having higher negative domains of psychological well-being than those with mild symptoms. Specifically, Cohen's $d$ effect sizes were large for some social resources and subjective well-being domains. Su et al. (2014) found the predictive effects of the CIT and BIT on various mental, physical, and behavioral problems, and people with higher scores on the thriving reported better self-reported health status, higher levels of physical functioning, fewer medical problems, and more frequent health behaviors. Therefore, individuals with psychological problems are more likely to experience lower levels of psychological well-being than those without. Overall, results from this study suggest that both the CIT and BIT models, measured by the Turkish version of the inventories, can be useful to understand the psychological wellbeing of the population of college students. This evidence has implications for the design of preventions and interventions to promote psychological well-being among young adults. Rather than a focus on the psychological 
problems in this population, addressing positive psychological health domains offers promise to foster a broad range of outcomes that will benefit individuals personally and in their studies.

\section{Implications and Limitations}

Assessments of psychological well-being offer an important resource for developing appropriate prevention and intervention strategies in higher education to promote young adults' strengths to improve more positive academic and psychosocial experiences. Mental health providers and leaders could use the CIT to perform comprehensive screening of psychological well-being. Considering the complete mental framework (Arslan, Allen, et al., 2020; Arslan \& Allen, 2020; Doll, 2008), the inventories could be integrated with negative psychological states to provide a more comprehensive picture for psychological well-being. Findings from the study also reported that individuals with severe psychological problems reported fewer positive psychological states, while experienced greater negative psychological states. Based on these results, mental health professionals could develop strategies to promote students' academic functioning and adjustment by providing resources to improve psychological well-being. Consequently, the study results provide further evidence for the use of both the CIT and CIT to assess the core assets of psychological well-being which may signal utility for researchers and practitioners who work to promote well-being and mental health in higher education. Therefore, the findings of this study contribute to the literature in this area by offering insight into thriving as a measure of the psychological well-being of young adults in Turkey.

Despite these significant implications for research and practice, the present study has a few limitations. Firstly, a cross-sectional approach was utilized, which does not mean causality. Future research should be performed to explore the variables associated with thriving using different methods (e.g., longitudinal research). Secondly, the study was conducted using a sample size of college students derived from a convenience sample from a state university in Turkey. This is another limitation of the study in respect to generalizability to other contexts. Therefore, further studies are warranted to examine the psychological well-being model in diverse samples. In addition, the sample mostly included female students, which may be considered as a limitation in this study. Future research should be performed with participants who are equally distributed in gender to provide the utility of the results. Finally, apart from student pathological symptoms, different psychological health indicators (e.g., social anxiety, substance use) could be used to provide further validity evidence and to understand the associations between psychological well-being domains and the outcomes.

\section{Ethical Standards}

\section{Compliance with Ethical Standards}

All study procedures involving human participants followed institutional and/or national research committee ethical standards and the 1964 Helsinki declaration and its later amendments or comparable ethical standards. This study has also been approved by the author's university Institutional Review Board.

\section{Author Contributions}

The author developed the concept for this manuscript, carried out the literature search, critically analyzed the data, wrote the manuscript, and proofread it.

\section{Declaration of Conflicting Interests}

The author(s) declared no potential conflicts of interest with respect to the research, authorship, and/or publication of this article.

\section{Funding}

The author(s) received no financial support for the research, authorship, and/or publication of this article.

\section{Data Availability}

The datasets generated during and/or analyzed during the current study are available from the corresponding author on reasonable request. 


\section{References}

Arslan, G. (2018). Psychological maltreatment, social acceptance, social connectedness, and subjective well-being in adolescents. Journal of Happiness Studies, 19(4), 983-1001.

Arslan, G. (2019). Exploring the effects of positive psychological strengths on psychological adjustment in adolescents. Child Indicators Research, 12(4), 1449-1464.

Arslan, G. (2020). Anlamlı Yaşam Ölçeğinin Geliştirilmesi: Anlamlı yaşama ilişkin kısa ve etkili bir ölçme aracı. Mehmet Akif Ersoy Üniversitesi Eğitim Fakültesi Dergisi, 56, 227-242. https://doi.org/10.21764/ maeuefd.773686

Arslan, G., \& Allen, K. A. (2021). School victimization, school belongingness, psychological well-being, and emotional problems in adolescents. Child Indicators Research. https://doi.org/10.1007/s12187-021-09813-4

Arslan, G., \& Allen, K.-A. (2020). Complete mental health in elementary school children: Understanding youth school functioning and adjustment. Current Psychology. https://doi.org/10.1007/s12144-020-00628-0

Arslan, G., \& Renshaw, T. L. (2018). Student subjective wellbeing as a predictor of adolescent problem behaviors: A comparison of first-order and second-order factor effects. Child Indicators Research, 11(2), 507-521.

Arslan, G., \& Y1ldırım, M. (2021). Meaning-Based Coping and Spirituality During the COVID-19 Pandemic: Mediating Effects on Subjective Well-Being. Frontiers in Psychology, 12, 1012.

Arslan, G., Allen, K.-A., Telef, B. B., \& Craig, H. (2020). Social-emotional health in higher education: a psychometric evaluation with Turkish students. British Journal of Guidance \& Counselling. https://doi.org/10.1080/03069885.2020.1789554

Arslan, G., Yıldırım, M., Karatas, Z., Kabasakal, Z., \& Kılınc, M. (2020). Meaningful living to promote complete mental health among university students in the context of the COVID-19 pandemic. International Journal of Mental Health and Addiction. https://doi.org/10.1007/s11469-020-00416-8

Aziz, I. A., \& Y1ldırım, M. (2020). Investigating relationship between psychological trait resilience and forgiveness among internally displaced persons. Psychology, Community \& Health, 8(1), 263-274.

Bieda, A., Hirschfeld, G., Schönfeld, P., Brailovskaia, J., Zhang, X. C., \& Margraf, J. (2017). Universal happiness? Cross-cultural measurement invariance of scales assessing positive mental health. Psychological Assessment, 29(4), 408-421. https://doi.org/10.1037/pas0000353

Butler, J., \& Kern, M. L. (2016). The PERMA-Profiler: A brief multidimensional measure of flourishing. International Journal of Wellbeing, 6(3), 1-48. https://doi.org/10.5502/ijw.v6i3.526

Carver, C. S. (2014). Optimism. In A. C. Michalos (Ed.), Encyclopedia of quality of life and well-being research (pp. 4500-4503). Springer Netherlands. https://doi.org/10.1007/978-94-007-0753-5_2018

Cohen, J. (1988). Statistical power analysis for the behavioralsciences (2nd ed.). Lawrence Erlbaum.

Curran, P. J., West, S. G., \& Finch, J. F. (1996). The robustness of test statistics to nonnormality and specification error in confirmatory factor analysis. Psychological Methods, 1(1), 16-29. https://doi.org/10.1037/1082989X.1.1.16

Derogatis, L. R., \& Fitzpatrick, M. (2004). The SCL-90-R, the Brief Symptom Inventory (BSI), and the BSI-18. In M. E. Maruish (Ed.), The use of psychological testing for treatment planning and outcomes assessment: Instruments for adults, Volume 3, 3rd ed. (pp. 1-41). Lawrence Erlbaum Associates Publishers.

Diener, E. (1984). Subjective well-being. Psychological Bulletin, 95(3), 542-575. https://doi.org/10.1037/00332909.95.3.542

Diener, E., Emmons, R. A., Larsen, R. J., \& Griffin, S. (1985). The satisfaction with life scale. Journal of Personality Assessment, 49(1), 71-75.

Diener, E., Suh, E. M., \& Lucas, R. E. (1999). Subjective well-being: three decades of progress. Psychological Bulletin, 125(2), 276-302.

Doll, B. (2008). The Dual-Factor Model of Mental Health in Youth. School Psychology Review, 37(1), 69-73. https://doi.org/10.1080/02796015.2008.12087909

Duan, W., Guan, Y., \& Gan, F. (2016). Brief Inventory of Thriving. Chinese Sociological Dialogue, 1(1), 15-31. https://doi.org/10.1177/2397200916665230

Furlong, M., Dowdy, E., Carnazzo, K., Bovery, B. L., \& Kim, E. (2014). Covitality: Fostering the Building Blocks of Complete Mental Health. Communique, 42(8), 1-28.

Hooper, D., Coughlan, J., \& Mullen, M. R. (2008). Structural equation modelling: Guidelines for determining model 
fit. Electronic Journal of Business Research Methods, 6(1), 53-60.

Keyes, C. L. M. (2003). Complete mental health: An agenda for the 21st century. In Flourishing: Positive psychology and the life well-lived. (pp. 293-312). American Psychological Association. https://doi.org/10.1037/10594-013

Kline, R. B. (2015). Principles and practice of structural equation modeling. Guilford .

Martins, L. M. D. G., \& Ferreira, M. C. (2018). Psychometric Properties of the Inventory of Thriving: Brief and Comprehensive Versions. Temas Em Psicologia, 26(3), 1573-1587. https://doi.org/10.9788/TP2018.3-15En

Renshaw, T. L., \& Arslan, G. (2019). Testing the psychological wellbeing and distress screener with Turkish adolescents. International Journal of School \& Educational Psychology, 7(3), 165-173.

Ryan, R. M., \& Deci, E. L. (2000). Self-determination theory and the facilitation of intrinsic motivation, social development, and well-being. American Psychologist, 55(1), 68-78. https://doi.org/10.1037/0003066X.55.1.68

Ryff, C. D., \& Keyes, C. L. M. (1995). The structure of psychological well-being revisited. Journal of Personality and Social Psychology, 69(4), 719-727. https://doi.org/10.1037/0022-3514.69.4.719

Scheier, M. F., \& Carver, C. S. (1985). Optimism, coping, and health: Assessment and implications of generalized outcome expectancies. Health Psychology. https://doi.org/10.1037//0278-6133.4.3.219

Sorgente, A., Zambelli, M., Tagliabue, S., \& Lanz, M. (2021). The comprehensive inventory of thriving: a systematic review of published validation studies and a replication study. Current Psychology. https://doi.org/10.1007/s12144-021-02065-Z

$\mathrm{Su}, \mathrm{R} .$, Tay, L., \& Diener, E. (2014). The development and validation of the Comprehensive Inventory of Thriving (CIT) and the Brief Inventory of Thriving (BIT). Applied Psychology: Health and Well-Being, 6(3), 251-279. https://doi.org/10.1111/aphw.12027

Wiese, C. W., Tay, L., Su, R., \& Diener, E. (2018). Measuring thriving across nations: Examining the measurement equivalence of the Comprehensive Inventory of Thriving (CIT) and the Brief Inventory of Thriving (BIT). Applied Psychology: Health and Well-Being, 10(1), 127-148. https://doi.org/10.1111/aphw.12119

Yıldırım, M., \& Arslan, G. (2020). Exploring the associations between resilience, dispositional hope, preventive behaviours, subjective well-being, and psychological health among adults during early stage of COVID19. Current Psychology, 1-11. Doi: https://doi.org/10.1007/s12144-020-01177-2

Yildırım, M., \& Arslan, G. (2021). A moderated mediation effect of stress-related growth and meaning in life in the association between coronavirus suffering and satisfaction with life: Development of the Stress-Related Growth Measure. Frontiers in psychology, 12, 529.

Yıldırım, M., Arslan, G., \& Ahmad Aziz, I. (2020). Why do people high in COVID-19 worry have more mental health disorders? The roles of resilience and meaning in life. Psychiatria Danubina, 32(3-4), 505-512.

Yıldırım, M., Arslan, G., \& Wong, P. T. (2021). Meaningful living, resilience, affective balance, and psychological health problems among Turkish young adults during coronavirus pandemic. Current Psychology. https://doi.org/10.1007/s12144-020-01244-8 